\title{
Two feathered dinosaurs from northeastern China
}

\author{
Ji Qiang*, Philip J. Currie †, Mark A. Norell $¥$ \& Ji Shu-An* \\ * National Geological Museum of China, Yangrou Hutong 15, Xisi, 100034 Beijing, People's Republic of China \\ $\dagger$ Royal Tyrrell Museum of Palaeontology, Box 7500, Drumheller, Alberta T0J 0Y0, Canada \\ $\ddagger$ American Museum of Natural History, Central Park West at 79th Street, New York, New York 10024-5192, USA
}

\begin{abstract}
Current controversy over the origin and early evolution of birds centres on whether or not they are derived from coelurosaurian theropod dinosaurs. Here we describe two theropods from the Upper Jurassic/Lower Cretaceous Chaomidianzi Formation of Liaoning province, China. Although both theropods have feathers, it is likely that neither was able to fly. Phylogenetic analysis indicates that they are both more primitive than the earliest known avialan (bird), Archaeopteryx. These new fossils represent stages in the evolution of birds from feathered, ground-living, bipedal dinosaurs.
\end{abstract}

\author{
Dinosauria Owen 1842 \\ Theropoda Marsh 1881 \\ Maniraptora Gauthier 1986 \\ Unnamed clade \\ Protarchaeopteryx robusta Ji \& Ji 1997
}

Holotype. National Geological Museum of China, NGMC 2125 (Figs 1, 2 and 3).

Locality and horizon. Sihetun area near Beipiao City, Liaoning, China. Jiulongsong Member of Chaomidianzi Formation, Jehol Group ${ }^{1}$. This underlies the Yixian Formation, the age of which has been determined to be Late Jurassic to Early Cretaceous ${ }^{3,4}$.

Diagnosis. Large straight premaxillary teeth, and short, bulbous maxillary and dentary teeth, all of which are primitively serrated. Rectrices form a fan at the end of the tail.

Description. The skull of Protarchaeopteryx is shorter than the femur (Table 1). There are four serrated premaxillary teeth (Fig. 1c), with crown heights of up to $12 \mathrm{~mm}$. Premaxillary teeth of coelophysids $^{5}$, compsognathids ${ }^{6,7}$ and early birds lack serrations, but premaxillary denticles are present in most other theropods. Six maxillary and seven dentary teeth are preserved (Fig. 1), all of which are less than a quarter the height of the premaxillary teeth. They most closely resemble those of Archaeoptery $x^{8}$ in shape (Figs $1 \mathrm{~b}, \mathrm{c}$ and $2 \mathrm{~b}, \mathrm{c})$, but have anterior and posterior serrations (7-10 serrations per $\mathrm{mm}$ ).

The amphicoelous posterior cervicals are the same length as the posterior dorsals, which have large pleurocoels. If the lengths of missing segments of the tail are accounted for, there were fewer than 28 caudals. Vertebrae increase in length from proximal to midcaudals, as in most non-avian coelurosaurs.

\section{Table 1 Lengths of elements in Protarchaeopteryx and Caudipteryx}

\section{Element} NGMC 2125 NGMC 97-4-A NGMC 97-9-A

Body length

Skull

Sternal plates

Humerus

Arm (humerus to end of phalange II-2)

Ilium

Ischium

Leg (femur to end of phalange III-4)

Femur

Tibia

Metatarsal III

\begin{tabular}{|c|c|c|}
\hline 690 & 890 & 725 \\
\hline 70 & 76 & 79 \\
\hline 25 & 36 & - \\
\hline 88 & 69 & 70 \\
\hline 297 & 214 & 220 \\
\hline 95 & 101 & - \\
\hline - & 77 & - \\
\hline 450 & 550 & 540 \\
\hline 122 & 147 & 149 \\
\hline 160 & 188 & 182 \\
\hline 160 & 188 & 182 \\
\hline 85 & 115 & 117 \\
\hline
\end{tabular}

Length measurements are given in millimetres. NGMC 2125, Protarchaeopteryx; NGMC 97.4-A and NGMC 97-9-A, Caudipteryx.
There are two thin, flat, featureless sternal plates. The clavicles are fused into a broad, U-shaped furcula (interclavicular angle is about $60^{\circ}$ ) as in Archaeopteryx, Confuciusornis and many non-avian theropods. The forelimb is shorter than the hindlimb. The arm is shorter (compared to the femur) than it is in birds, but is longer than those of long-armed non-avian coelurosaurs such as dromaeosaurids and oviraptorids (Table 2). The better preserved right wrist of NGMC 2125 has a single semilunate carpal capping the first two metacarpals. The hand has the normal theropod phalangeal formula of 2-3-4-x-x. The manus is longer than either the humerus or radius. Compared to femur length, the hand is more elongate than those of any theropods other than Archaeoptery $x^{9}$ and Confuciusornis (Table 2). More advanced birds such as Cathayornis have shorter hands ${ }^{10}$. Phalanges III-1 and III-2 in the hand of Protarchaeopteryx are almost the same size, and are about half the length of III-3. The unguals are long and sharp, and keratinous sheaths are preserved on two of them.

The preacetabular blade of the ilium is about the same length as the postacetabular blade. The pubic boot expands posteriorly. Anteriorly, the pubis is not exposed.

The tibia is longer than the femur, as it is in most advanced theropods and early birds. It is not known if the fibula extended to the tarsus.

The metatarsals are separate from each other and the distal tarsals. Metatarsal I is centred halfway up the posteromedial edge of the second metatarsal. In perching birds such as Sinornis ${ }^{9}$, metatarsal I is positioned near the end of metatarsal II and is retroverted. Its condition in Archaeopteryx is intermediate. Pedal unguals are smaller than manual unguals.

A clump of at least six plumulaceous feathers is preserved anterior

Table 2 Relative proportions of elements in relevant avian and non-avian theropods

\begin{tabular}{|c|c|c|c|c|c|c|c|}
\hline Element & Drom & Ov & Tro & $C x$ & $P x$ & $A x$ & Con \\
\hline $\mathrm{Arm} / \mathrm{F}$ & $1.8-2.6$ & $1.5-1.8$ & 1.8 & 1.5 & 2.4 & 3.7 & 3.9 \\
\hline $\mathrm{S} / \mathrm{H}$ & 0.8 & $1.0-1.2$ & - & 1.1 & - & 0.6 & 0.8 \\
\hline $\mathrm{R} / \mathrm{H}$ & $0.7-0.8$ & $0.8-0.9$ & $0.6-0.7$ & 0.9 & 0.8 & 0.9 & 0.8 \\
\hline Manus/H & $0.9-1.2$ & $1.2-1.4$ & 1.3 & 1.2 & 1.6 & 1.2 & 1.3 \\
\hline Manus/F & 1.0 & $0.7-1.0$ & 0.8 & 0.6 & 1.2 & 1.5 & 1.6 \\
\hline $\mathrm{Mcl} / \mathrm{Mcll}$ & $0.4-0.5$ & $0.4-0.6$ & 0.3 & 0.4 & 0.4 & 0.3 & 0.4 \\
\hline $\mathrm{T} / \mathrm{F}$ & $1.1-1.4$ & 1.2 & $1.1-1.2$ & 1.2 & 1.3 & 1.4 & 1.1 \\
\hline $\mathrm{Leg} / \mathrm{F}$ & 3.6 & 3.3 & 3.8 & 3.7 & 3.7 & 3.8 & 3.3 \\
\hline $\mathrm{Leg} / \mathrm{arm}$ & 1.4 & 1.7 & 2.1 & 2.5 & 1.5 & 1.1 & 0.8 \\
\hline
\end{tabular}

All data were collected from original specimens by P.J.C. Ax, Archaeopteryx; Con, Confuciusornis; Cx, Caudipteryx; Drom, dromaeosaurids; F, femur; $H$, humerus; L, length; Confuciusornis; Cx, Caudipteryx; Drom, dromaeosaurids; F, femur; H, humerus; L, length;
Mc, metacarpal; Ov, oviraptorids; Px, Protarchaeopteryx; R, radius; S, scapula; T, tibia; Tro, troodontids. 
to the chest, with some showing well-developed vanes (Fig. 3a). Evenly distributed plumulaceous feathers up to $27 \mathrm{~mm}$ long are associated with ten proximal caudal vertebrae. Twenty-millimetre plumulaceous feathers are preserved along the lateral side of the right femur and the proximal end of the left femur.

Parts of more than twelve rectrices are preserved ${ }^{11}$ attached to the distal caudals. One of the symmetrical tail feathers (Fig. 3b) extends $132 \mathrm{~mm}$ from the closest tail vertebra, and has a long tapering rachis with a basal diameter of $1.5 \mathrm{~mm}$. The well-formed pennaceous vanes of Protarchaeopteryx show that barbules were present. The vane is $5.3 \mathrm{~mm}$ wide on either side of the rachis. At midshaft, five barbs come off the rachis every $5 \mathrm{~mm}$ (compared with six in Archaeopteryx), and individual barbs are $15 \mathrm{~mm}$ long. As in modern rectrices, the barbs at the base of the feather are plumulaceous.

\section{Maniraptora Gauthier 1986 Unnamed clade}

Diagnosis. The derived presence of a short tail (less than 23 caudal vertebrae) and arms with remiges attached to the second digit.

\section{Caudipteryx zoui gen. et sp. nov.}

Etymology. 'Caudipteryx' means 'tail feather', 'zoui': refers to Zou
Jiahua, vice-premier of China and an avid supporter of the scientific work in Liaoning.

Holotype. NGMC 97-4-A (Figs 4 and 5b).

Paratype. NGMC 97-9-A (Fig. 5d).

Locality and horizon. Sihetun area, Liaoning. Jiulongsong Member of the Chaomidianzi Formation.

Diagnosis. Elongate, hooked premaxillary teeth with broad roots; maxilla and dentary edentulous. Tail short (one-quarter of the length of the body). Arm is long for a non-avian theropod; short manual claws. Leg-to-arm ratio, 2.5.

Description. The skulls of both specimens of Caudipteryx are shorter than the corresponding femora because of a reduction in the length of the antorbital region. The relatively large premaxilla (Figs 6 and 7) borders most of the large external naris. The maxilla and nasal are short, but the frontals and jugals are long. The lacrimal of NGMC 97-4-A is an inverted L-shaped, pneumatic bone. Scleral plates are preserved in the 20 -mm-diameter orbits of both specimens. The tall quadratojugal seems to have contacted the squamosal and abutted the lateral surface of the quadrate. The single-headed quadrate is vertical in orientation. The ectopterygoid has a normal theropod hooklike jugal process. There is a broad, beak-like margin at the symphysis of the dentaries. Posteriorly, the dentary bifurcates around a large external mandibular fenestra as in oviraptorids. A

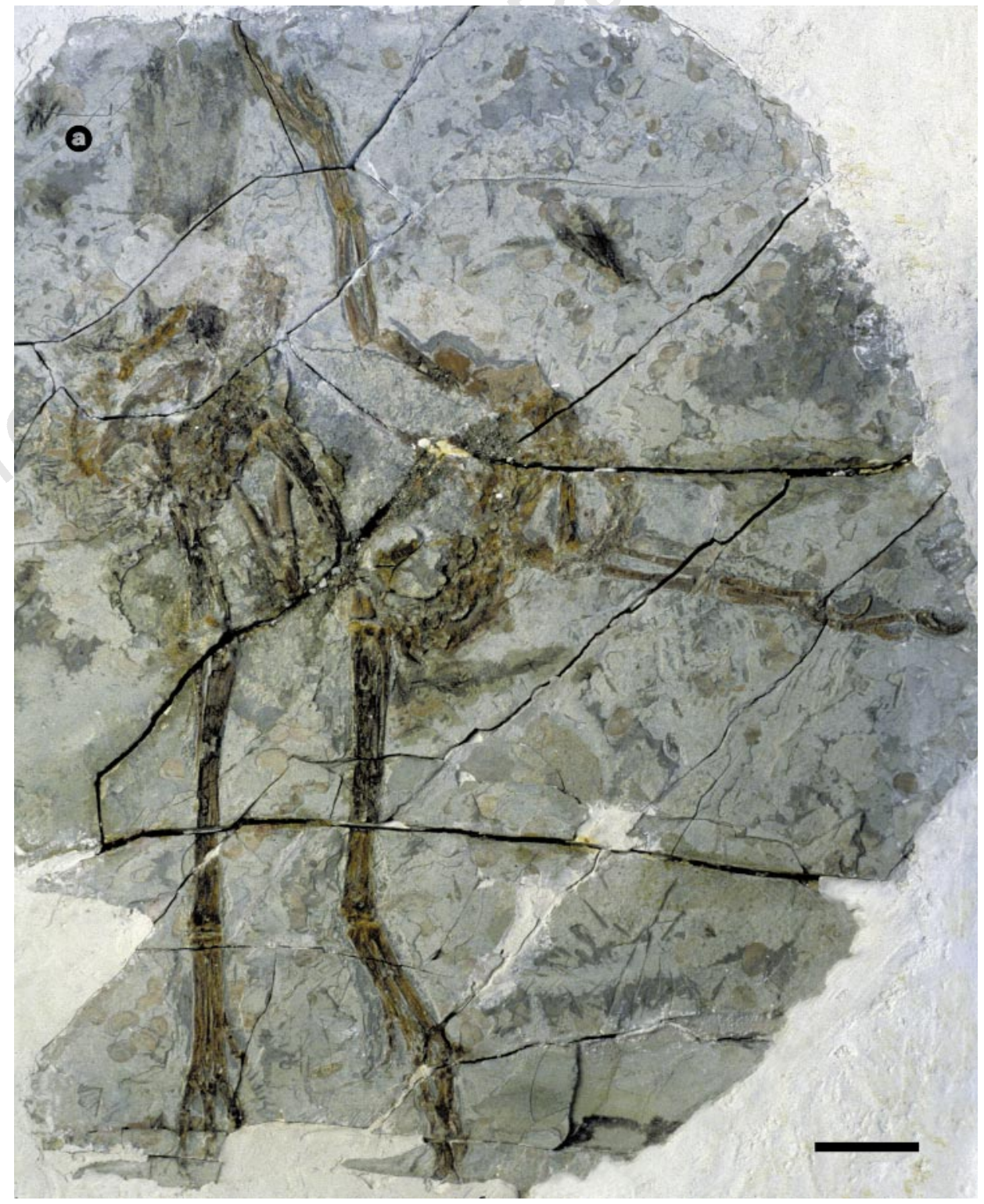




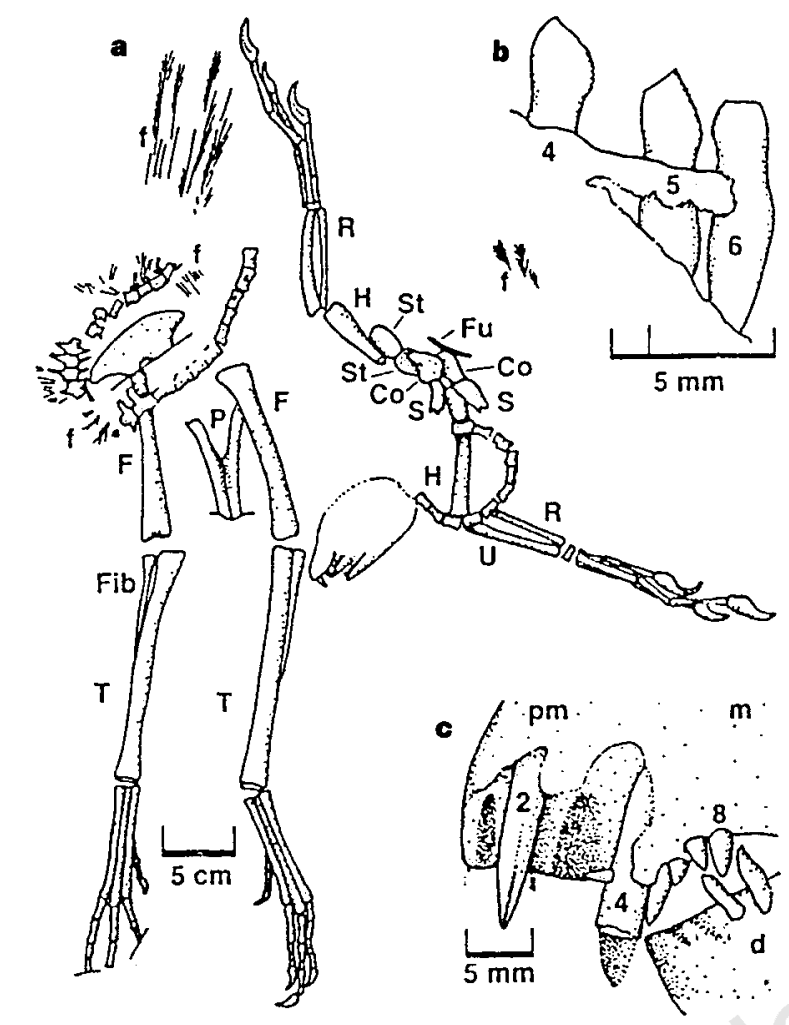

4 Figure 2 Protarchaeopteryx robusta. a, Outline of the specimen shown in Fig. 1a. b. Outline of the left dentary teeth shown in Fig. 1b. c. Drawing of the front of the jaws, showing the large size of the premaxillary teeth compared with maxillary and dentary ones. Abbreviations: Co, coracoid; d, dentary; F, femur; f, feathers; Fib, fibula; Fu, furcula; $\mathrm{H}$, humerus; $m$, maxilla; $\mathrm{P}$, pubis; $\mathrm{pm}$, premaxilla; $\mathrm{R}$, radius; S, scapula; St, sternal plate; T, tibia; U, ulna. Numbers represent tooth positions from front to back.
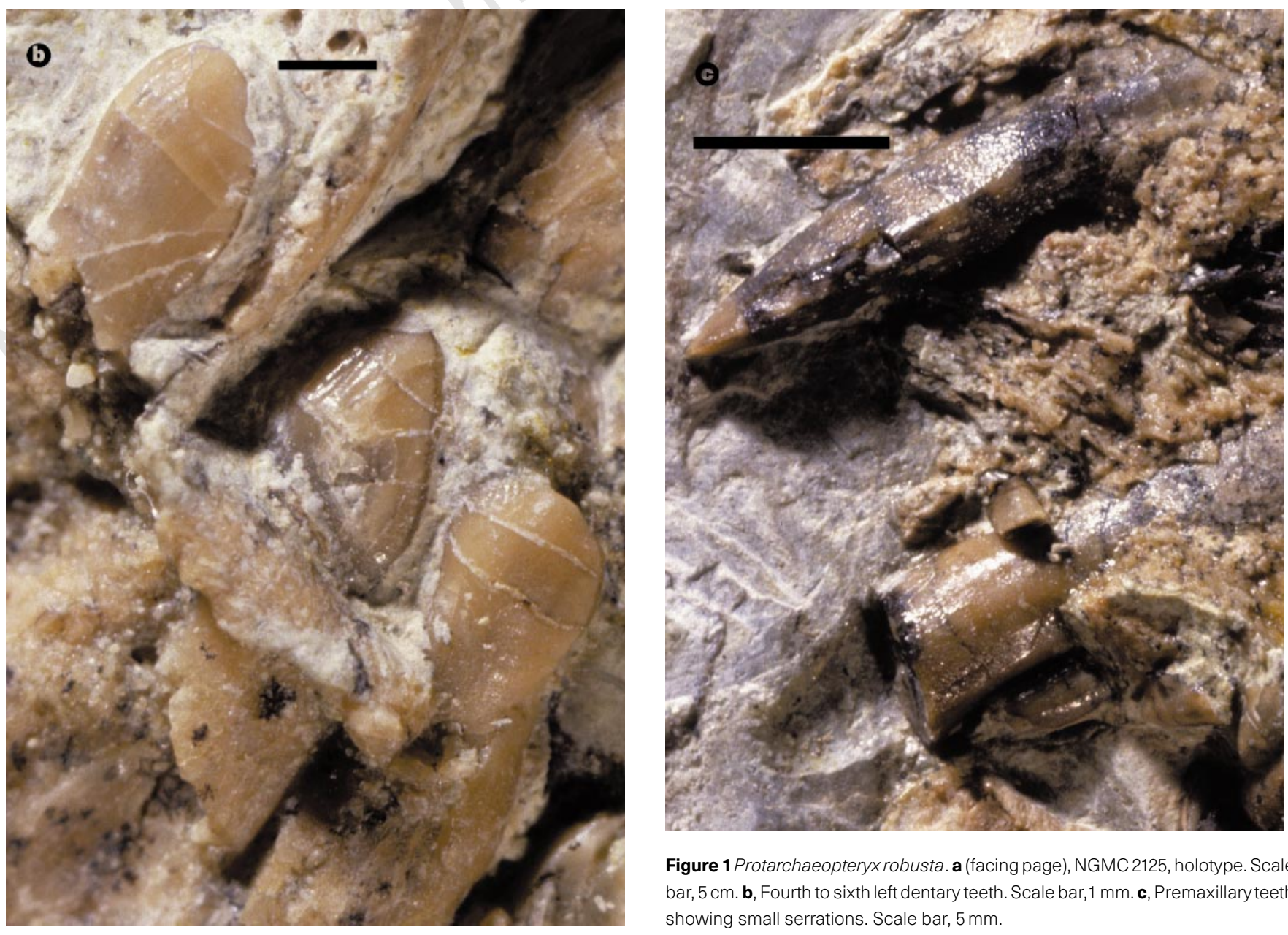

Figure 1 Protarchaeopteryx robusta. a (facing page), NGMC 2125, holotype. Scale bar, $5 \mathrm{~cm}$. b. Fourth to sixth left dentary teeth. Scale bar, $1 \mathrm{~mm}$. c, Premaxillary teeth showing small serrations. Scale bar, $5 \mathrm{~mm}$. 
well-developed, sliding intramandibular joint is present between dentary and surangular.

There are four teeth in each premaxilla. They have elongate, needlelike crowns, and the roots are five times wider than the crowns (Fig. 7b). The lingual wall of the root of the third right tooth has been resorbed for the crown of a replacement tooth. The teeth seem to have been procumbent, with an inflection at the gumline. Caudipteryx had no maxillary or dentary teeth.

There are ten amphicoelous cervical vertebrae and five sacrals as in most non-avian theropods and Archaeopteryx ${ }^{8,12}$. The tail of NGMC 97-4-A is articulated and well-preserved, and includes 22 vertebrae, as in Archaeopteryx. It is shorter than the 30-segment tails of oviraptorids. Most other non-avian theropods have much longer tails. Caudals do not become longer posteriorly, as they do in most non-avian theropods and Archaeopteryx. Almost two-thirds of the tail of NGMC 97-4-A is preserved as a straight rod, but the vertebrae are not fused. The first six haemal spines are elongate, rodlike structures. More posterior haemal spines decrease in height, but expand anteriorly and posteriorly (Fig. 5a).

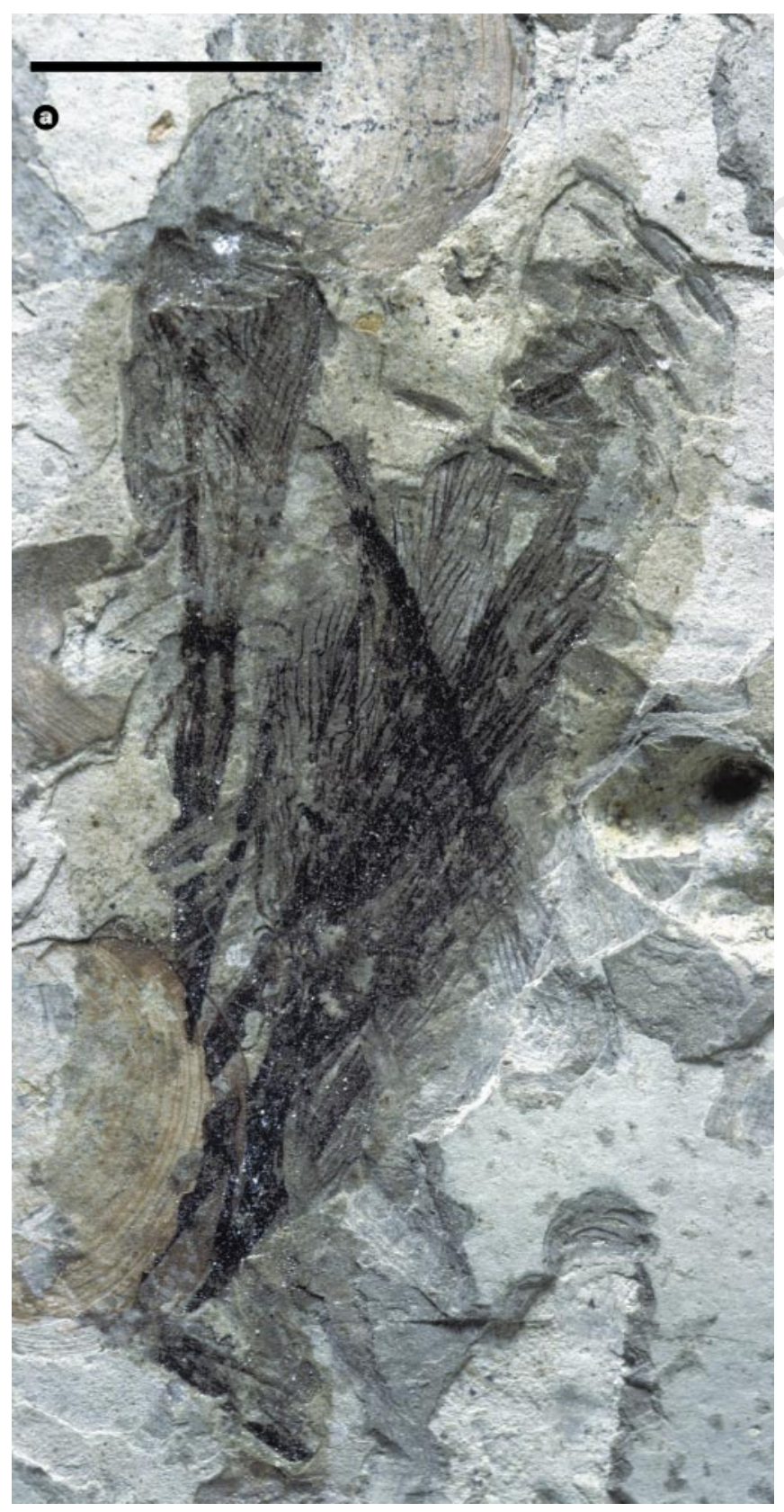

Each segment of gastralia is formed by two pairs of slender, tapering rods, as in all non-avian theropods, Protarchaeopteryx and early birds $\mathrm{s}^{8,9,13,14}$.

The paired sternals are similar to those of dromaeosaurids and oviraptorids. Confuciusornis had a relatively larger, unkeeled sternum. Some short bones with slight expansions at each end are found near the sternal plates of NGMC 97-9-A, and may be sternal ribs.

The scapula is longer than the humerus, whereas the scapula-tohumerus ratio is less than 1.0 in flying birds (Table 2) because of humerus elongation. The clavicles are fused into a broad, $\mathrm{U}$-shaped furcula in NGMC 97-9-A as in Archaeopteryx, Confuciusornis and many non-avian theropods.

Compared to the humerus, forearm length is similar to that in oviraptorosaurs (Table 2), Archaeopteryx and Protarchaeopteryx. In more advanced birds ${ }^{15,16}$, the radius is longer than the humerus. The external surface of the ulna, as in Archaeoptery $x^{8}$, lacks any evidence of quill nodes.

There are three carpals preserved in NGMC 97-4-A, including a large semi-lunate one that caps metacarpals I and II as in dromaeosaurids, oviraptorids, troodontids, Archaeopteryx, Confuciusornis and other birds. Four carpals have been recognized in Archaeoptery $x^{12}$. A large triangular radiale sits between the semilunate and the radius. A small carpal articulates with the third metacarpal. A thin wedge of bone at the end of the ulna is probably a fragment of gastralia.

The unfused metacarpals and digits of both specimens are well preserved. The third metacarpal is almost as long as the second, but is more slender. The hand has the normal theropod phalangeal

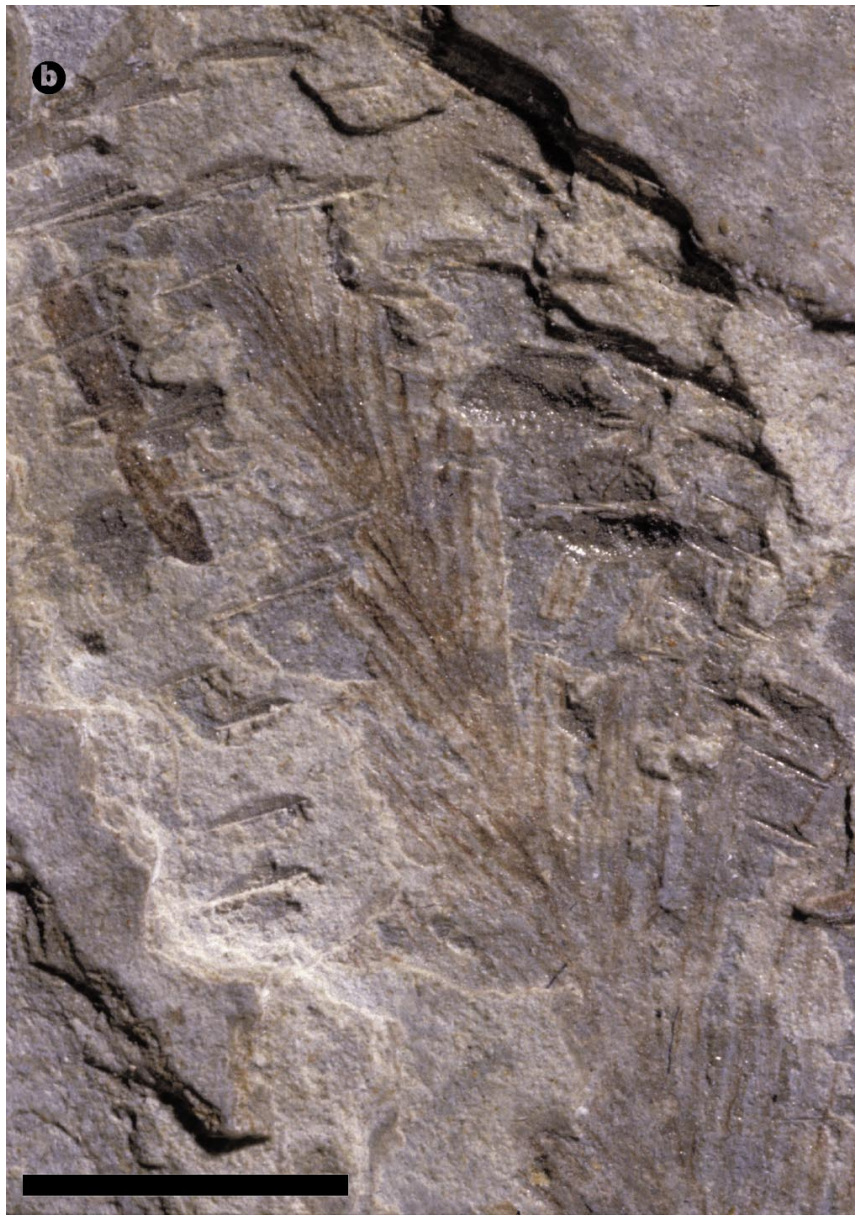

Figure 3 Protarchaeopteryx robusta, NGMC 2125. a, Contour and plumulaceous feathers. Scale bar, $10 \mathrm{~mm}$. b. Rectrices. Scale bar, $5 \mathrm{~mm}$. 
formula of 2-3-4-x-x. The manus is longer than either the humerus or the radius, which is a primitive characteristic shared with most non-avian coelurosaurs, Archaeopteryx ${ }^{9}$ and Confuciusornis. In contrast with Archaeopteryx, Confuciusornis, Protarchaeopteryx and many non-avian theropods (ornithomimids, troodontids, dromaeosaurids and oviraptorids), the manus is relatively short compared with the femur.

The curved second manual ungual is about two-thirds the size of the same element in Protarchaeopteryx, and is less than $70 \%$ the length of the penultimate phalanx.

Pelvic elements are unfused, as they are in all non-avian theropods (except some ceratosaurs) and the most primitive birds ${ }^{16}$. The acetabulum is large, comprising almost a quarter of the length of the ilium (the ratio of acetabulum-to-ilium length is less than 0.11 in $\left.\operatorname{birds}^{17}\right)$. It has a deeper, shorter, more squared-off pre- acetabular region than that of Protarchaeopteryx, and closely resembles the ilium of dromaeosaurids ${ }^{18}$. The tapering postacetabular region is lower and longer than the preacetabular. The pubic penduncle is anteroposteriorly elongated, and has a notch (Figs 4 and 5b) in the ventral margin that divides the suture into two surfaces. This notch and the deep pubic peduncle of the ischium are characteristic of opisthopubic pelves. The ischium has no dorsal process such as that found in Archaeopteryx and Confuciusornis, and the shaft curves down and back. A well-developed ventromedial flange is present, perhaps indicating contact between elements. In general appearance, the ischium most closely resembles those of non-avian coelurosaurs.

The ratio of hindlimb-to-forelimb length is higher than in other coelurosaurs (Table 2) except alvarezsaurids ${ }^{19}$, which had exceptionally short arms. The greater trochanter is separated from the

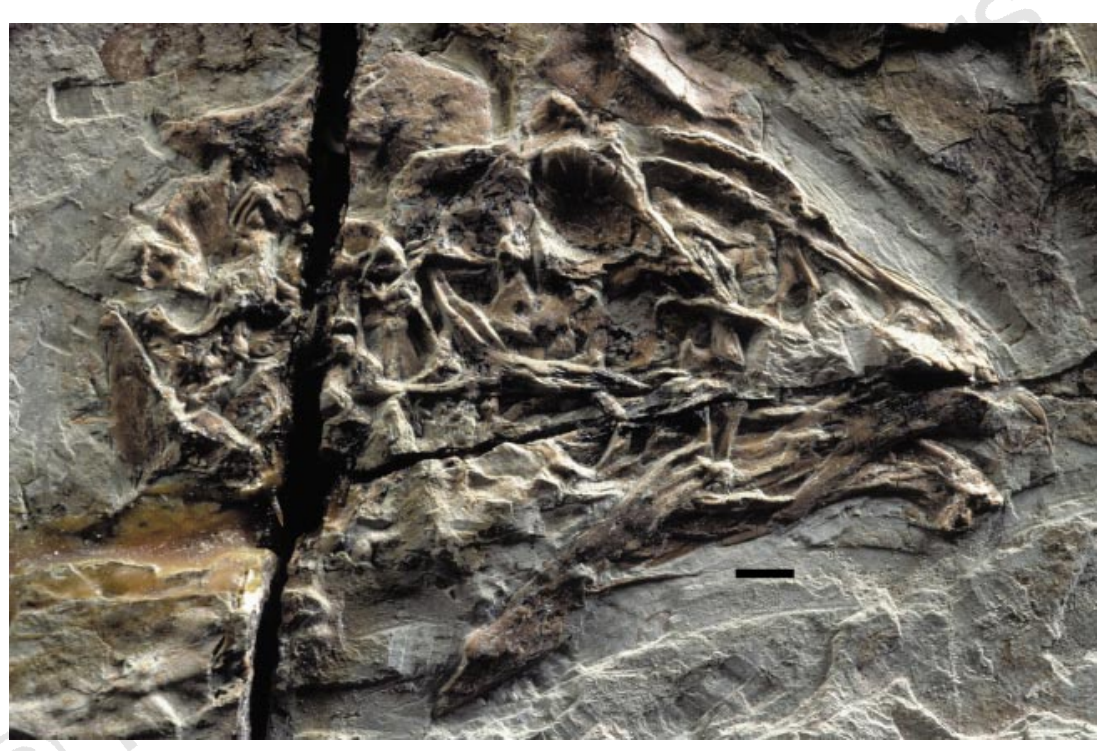

Figure 6 Caudipteryx zoui, skull of NGMC 97-9-A in right lateral view. Scale bar, $1 \mathrm{~cm}$.

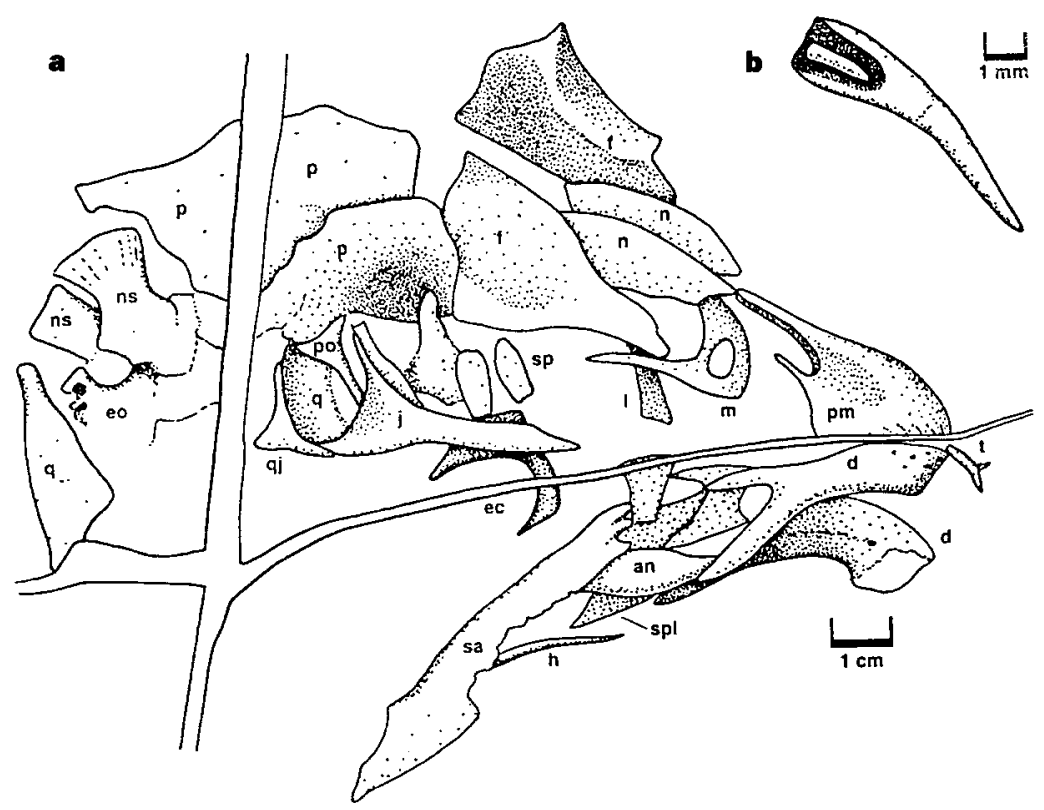

Figure 7 Caudipteryx zou. a, Sketch of skull shown in Fig. 6. b. Premaxillary tooth of NGMC 97-4-A, showing resorption pit and germ tooth. Abbreviations: an, angular; d, dentary; ec, ectopterygoid; eo, exoccipital; f, frontal; h, hyoid; j, jugal; ।, lacrymal; m, maxilla; $n$, nasal; ns, neural spine; $p$, parietal; pm, premaxilla; po, postorbital; q, quadrate; qj, quadratojugal; sa, surangular; sp, scleral plate; spl, splenial; t, premaxillary teeth. 
lesser trochanter of the femur by a shallow notch, and forms a raised, semi-lunate rim that is similar to the trochanter femoris of birds, troodontids and avimimids.

None of the fibulae is complete, but NGMC 97-9-A has a socket for the distal end of the fibula formed by the calcaneum, astragalus and tibia. The astragalus is not fused to the tibia. The ascending process of NGMC 97-9-A (Fig. 5e) extends $22 \%$ of the distance up the front surface of the tibia, compared with $12 \%$ in Archaeoptery $x^{12}$. As in Archaeopteryx ${ }^{8}$, Confuciusornis ${ }^{10}$ and most non-avian theropods, the calcaneum is retained as a separate, disk-like element. Two distal tarsals are positioned over the third and fourth metatarsals, as in Archaeopteryx, Buluochia ${ }^{20}$ and all non-avian theropods that lack fused tarsometatarsals.

The metatarsals of Caudipteryx are not fused; this is the plesiomorphic condition expressed in most non-avian theropods. Metatarsal I is centred about a quarter of the way up the posteromedial corner of the second metatarsal. The third is the longest of the metatarsals, and in anterior view completely separates the second and fourth metatarsals, unlike in the arctometatarsalian condition of many theropods ${ }^{21}$. Nevertheless, at midshaft the third metatarsal is thin anteroposteriorly and is triangular in cross-section. The pedal unguals are triangular in cross-section and are about the same size as the manual unguals.

At least fourteen remiges are attached to the second metacarpal, phalanx II-1, and the base of phalanx II-2 of NGMC 97-4-A (Fig. 8a). Each remex has a well-preserved rachis and vane. The most distal remex is less than $30 \mathrm{~mm}$ long. The second most distal remex is $63.5 \mathrm{~mm}$ long, is symmetrical, and has $6.5-\mathrm{mm}$-long barbs on either side of the rachis. The fourth most distal primary remex is $95 \mathrm{~mm}$ long and is longer than the humerus. Unfortunately, the distal ends of the remaining remiges are not preserved. In flying birds (even Archaeopteryx ${ }^{12}$ ), each remex is longer than they are in Caudipteryx, and the most distal remiges are the longest. For example, the remiges of Archaeoptery $x^{22}$ are more than double the length of the femur. The barbs on either side of the rachis are symmetrical, contrasting with Archaeopteryx and modern flying birds ${ }^{23}$.

The holotype preserves ten complete and two partial rectrices. Eleven are attached to the left side of the tail, and were probably paired with another eleven feathers on the right side (only the terminal feather is preserved). Two rectrices are attached to each side of the last five or six caudal vertebrae, but not to more anterior ones. NGMC 97-9-A preserves most of nine retrices. In Archaeopteryx, rectrices are associated with all but the first five or six caudals ${ }^{12,22}$. Each rachis has a basal diameter of $0.74 \mathrm{~mm}$ and tapers distally. All the feathers appear to be symmetrical (Fig. 8b), although in most cases the tips of the barbs of adjacent feathers overlap. The vane of the sixth feather is $6 \mathrm{~mm}$ wide on either side of the rachis.

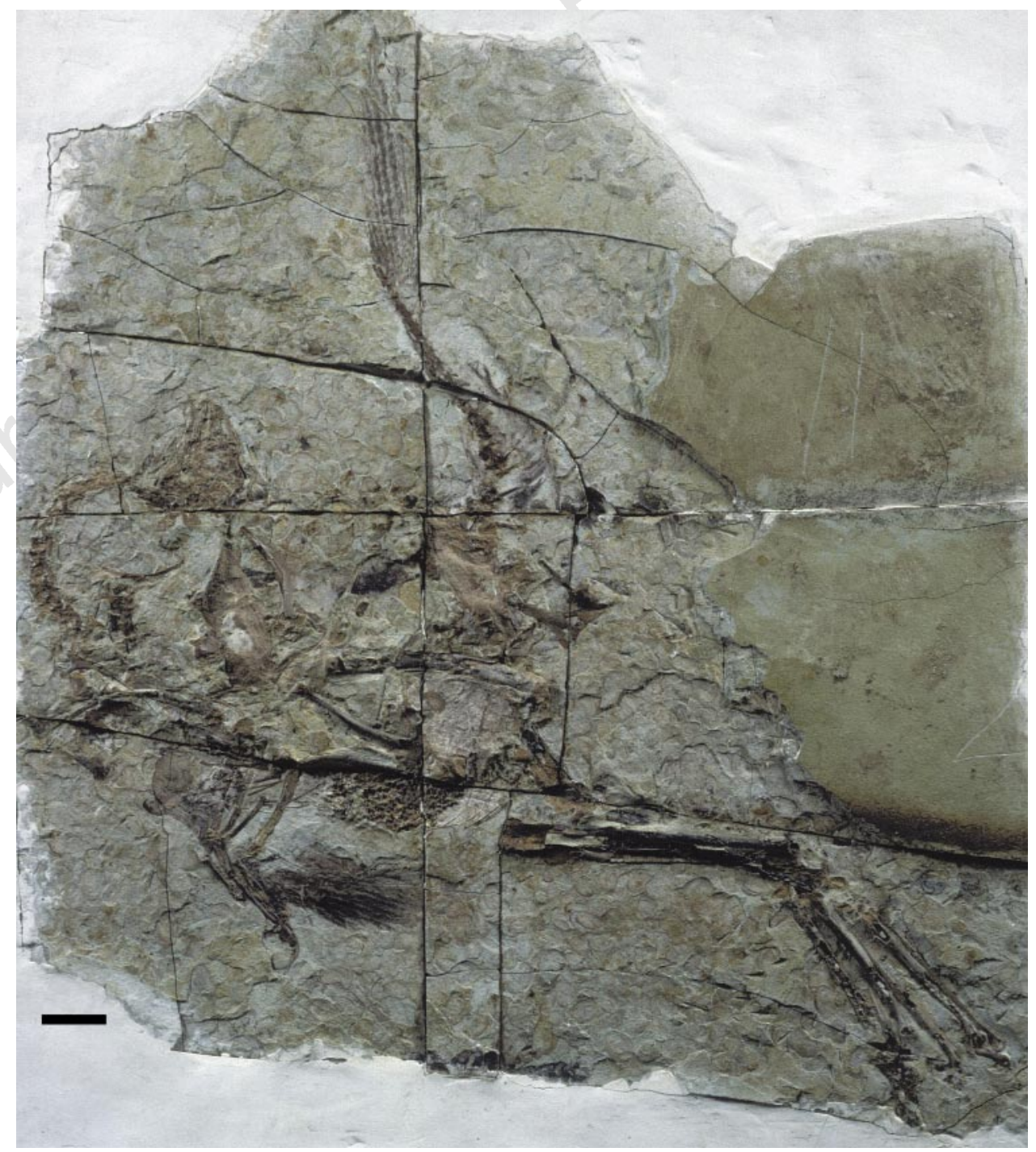

Figure 4 Caudipteryx zoui, holotype, NGMC 97-4-A. Scale bar, $5 \mathrm{~cm}$. 
The body of NGMC 97-4-A, especially the hips and the base of the tail, is covered by small, plumulaceous feathers of up to $14 \mathrm{~mm}$ long.

Both specimens have concentrations of small polished and rounded pebbles in the stomach region. These gastroliths are up to $4.5 \mathrm{~mm}$ in diameter, although most are considerably less than $4 \mathrm{~mm}$ wide.

\section{Phylogenetic analysis}

We examined the systematic positions of Protarchaeopteryx and Caudipteryx by coding these specimens for the 90 characters used in an analysis of avialan phylogeny ${ }^{24}$ (for a matrix of these characters, see Supplementary Information). Characters were unordered, and a tree was produced using the branch-and-bound option of PAUP ${ }^{25}$. We rooted the tree with Velociraptorinae ${ }^{26,27}$. A single tree resulted with a length of 110 steps, a retention index of 0.849 and a consistency index of 0.855. Analysis shows Caudipteryx to be the sister group to the Avialae, and Protarchaeopteryx to be unresolved from the Velociraptorinae root (Fig. 9). The placement of Protarchaeopteryx as the sister group to Caudipteryx + Avialae, as the sister group to Velociraptorinae, or as the sister group to Velociraptorinae + (Caudipteryx + Avialae $)$ are equally well supported by the data. Characters that define the Caudipteryx + Avialae clade in the shortest tree include unambiguous (uninfluenced by missing data or optimization) characters 2 and 12 and several more ambiguous ones (characters 4, 5, 10, 11, 15, 19, 24, 37, 85 and 86). Caudipteryx is separated from the Avialae by three unambiguous characters $(7,8$ and 71$)$ and additional ambiguous ones (characters $5,6,9,10,11,18,24,39,40,56$ and 69). The important characteristic of this phylogeny is that the Avialae (not including Protarchaeopteryx and Caudipteryx) is monophyletic; this placement is supported by the unequivocal presence of a quadratojugal that is joined to the quadrate by a ligament ${ }^{17}$ (character 7 ), the absence of a quadratojugal squamosal contact (character 8 ) and a reduced or absent process of the ischium (character 71 ).

As characters dealing with feathers cannot be scored relative to outgroup conditions, they were not used in the phylogenetic analysis. However, our analysis indicates that feathers can no longer be used in the diagnosis of the Avialae.

\section{Discussion}

The three Protarchaeopteryx and Caudipteryx individuals were close to maturity at the time of death. The neural spines seem to be fused to cervical and dorsal centra in Protarchaeopteryx. Sternal plates ossify late in the ontogeny of non-avian theropods, and are present in both Caudipteryx and Protarchaeopteryx. Well-ossified sternal ribs, wrist bones and ankle bones in Caudipteryx also indicate the maturity of the specimens.

The remiges of Caudipteryx and the rectrices of both

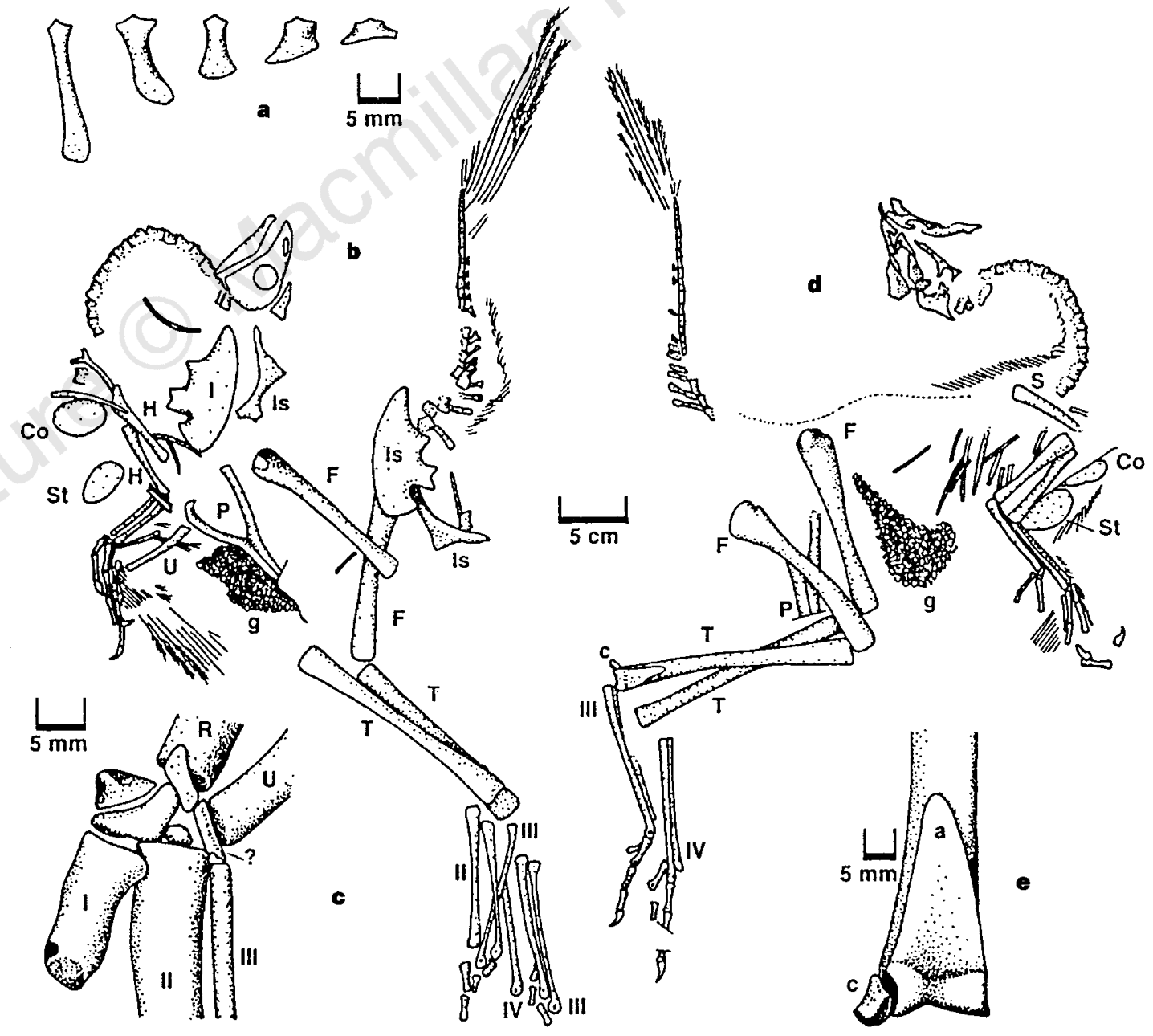

Figure 5 Caudipteryx zoui. a, Haemal spines from the fourth, sixth, eighth, eleventh and thirteenth caudal vertebrae (from left to right) of NGMC 97-4-A in left lateral view. b. Drawing of the specimen shown in Fig. 4a. c, Wrist of NGMC 97-4A. d, Drawing of NGMC 97-9-A. e, Proximal tarsals of NGMC 97-9-A. Abbrevia- tions: a, astragalus; c, calcaneum; Co, coracoid; F, femur; g, gastroliths; $H$, humerus; I, ilium; Is, ischium; P, pubis; $R$, radius; $S$, scapula; St, sternal plate; T, tibia; U, ulna;?, possibly fragment of gastralia. Roman numerals represent digit numbers. 

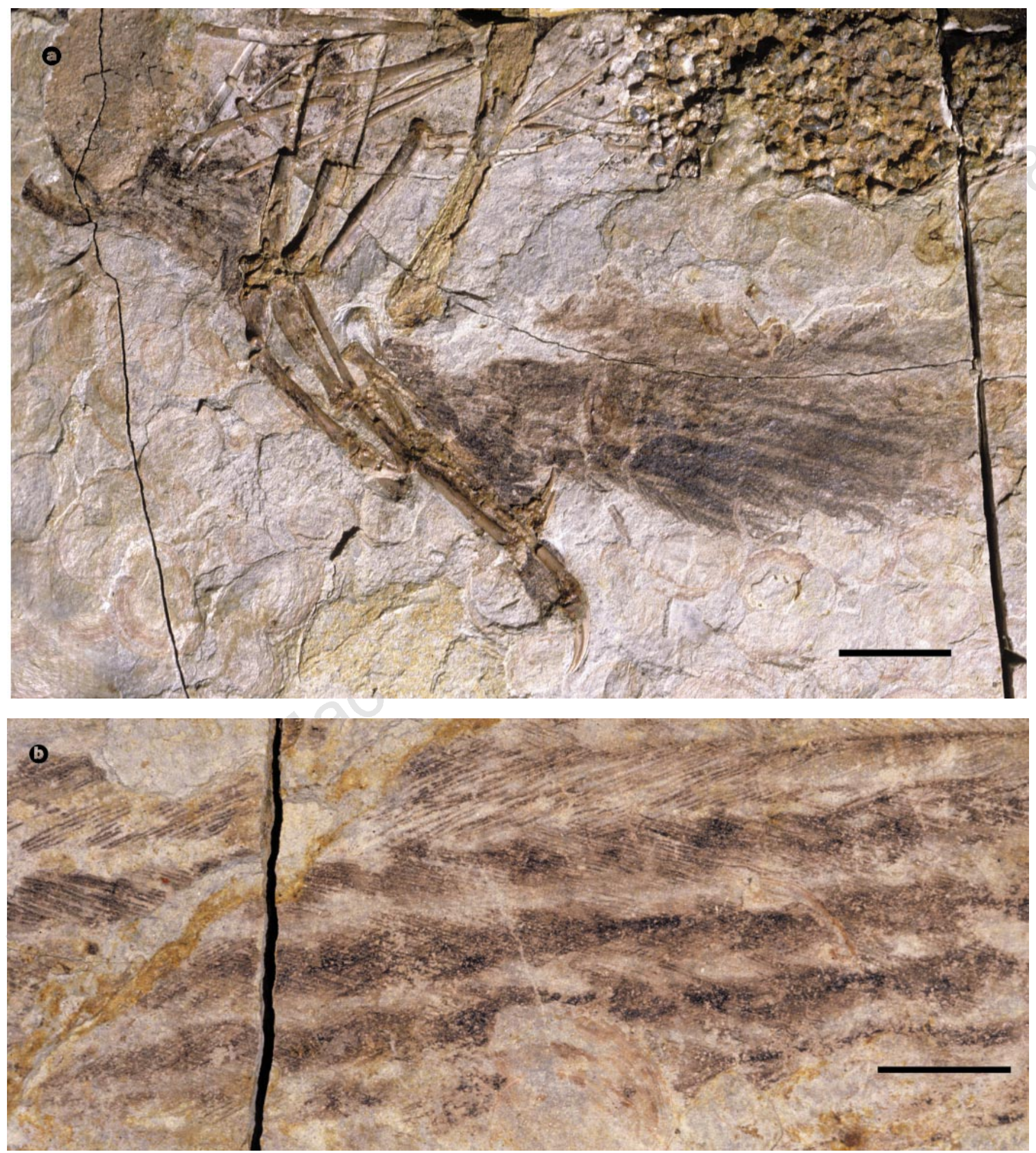

Figure 8 Feathers of Caudipteryx zoui, NGMC 97-4-A. a, Remiges of left arm. Scale bar, $1.75 \mathrm{~cm}$. b, Rectrices, showing colour banding. Scale bar, $1 \mathrm{~cm}$.

Protarchaeopteryx and Caudipteryx have symmetrical veins, whereas even those of Archaeopteryx are asymmetrical. Birds with asymmetrical feathers are generally considered to be capable of flight ${ }^{23}$, but it is possible that an animal with symmetrical feathers could also fly. Relative arm length of Protarchaeopteryx is shorter than that of Archaeopteryx, but is longer than in non-avian coelurosaurs. The arms of Caudipteryx, in contrast, are shorter than those of most non-avian coelurosaurs; the remiges are only slightly longer than the humerus; and the distal remiges are shorter than more proximal ones. It seems unlikely that this animal was capable of active flight. The relatively long legs of Protarchaeopteryx and Caudipteryx, both of which have the hallux positioned high and orientated anteromedially, indicate that they were ground-dwelling runners.

Paired rectrices of Protarchaeopteryx and Caudipteryx are restricted to the end of the tail, whereas in Archaeopteryx they extend over more than two-thirds the length of the tail ${ }^{12}$. Wherever preservation made it possible, we found semi-plumes and downlike feathers around the periphery of the bodies, suggesting that 


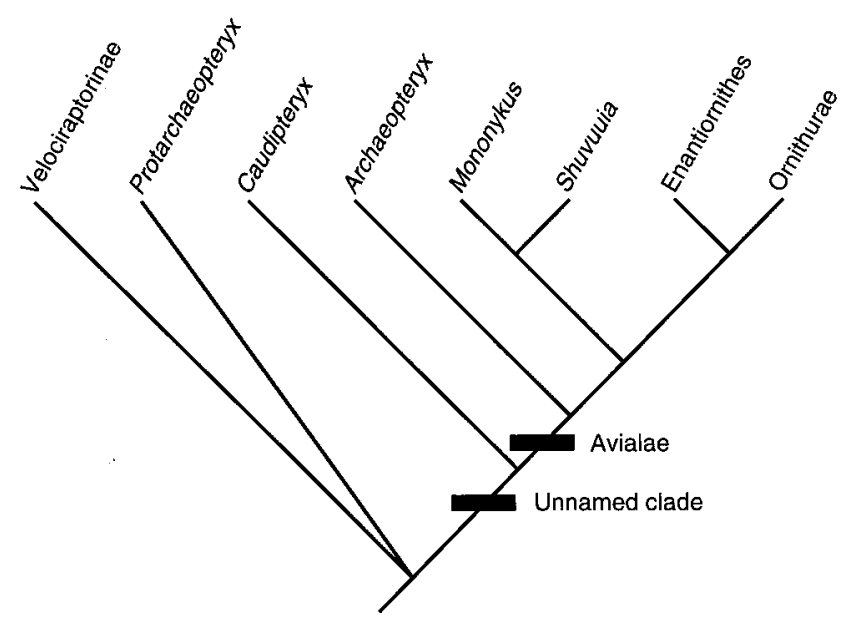

Figure 9 Cladogram of proposed relationships of Protoarchaeopteryx and Caudipteryx. This tree is based on 90 characters and has a length of 110 steps.

most of the bodies were feather-covered, possibly like Archaeoptery $x^{28}$. Feathers found with Otogornis ${ }^{29}$ were also apparently plumulaceous. Plumulaceous and downy feathers cover the bodies of Protarchaeopteryx and Caudipteryx, and possibly that of Sinosauropteryx as well ${ }^{7}$. This suggests that the original function of feathers was insulation.

Phylogenetic analysis shows that both Caudipteryx and Protarchaeopteryx lie outside Avialae and are non-avian coelurosaurs. This indicates that feathers are irrelevant in the diagnosis of birds. It can no longer be certain that isolated down and semi-plume feathers ${ }^{30-33}$ discovered in Mesozoic rocks belonged to birds rather than to non-avian dinosaurs. Furthermore, the presence of feathers on flightless theropods suggests that the hypothesis that feathers and flight evolved together is incorrect. Finally, the presence of remiges, rectrices and plumulaceous feathers on non-avian theropods provides unambiguous evidence supporting the theory that birds are the direct descendants of theropod dinosaurs.

Received 19 January; accepted 27 May 1998

1. Ji, Q. et al. On the sequence and age of the protobird bearing deposits in the Sihetun-Jianshangou area Beipao, western Liaoning. Prof. Pap. Strat. Paleo. (in the press).

2. Hou, L.-H., Zhou, Z.-H., Martin, L. D. \& Feduccia, A. A beaked bird from the Jurassic of China Nature 377, 616-618 (1995).

3. Smith, P. E. et al. Dates and rates in ancient lakes: ${ }^{40} \mathrm{Ar}^{39}{ }^{39} \mathrm{Ar}$ evidence for an Early Cretaceous age for the Jehol Group, northeast China. Can. J. Earth Sci. 32, 1426-1431 (1995).

4. Smith, J. B., Hailu, Y. \& Dodson, P. in The Dinofest Symposium, Abstracts (eds Wolberg, D. L. et al.) 55 (Academy of Natural Sciences, Philadelphia, 1998).
5. Colbert, E. H. The Triassic dinosaur Coelophysis. Bull. Mus. N. Arizona 57, 1-160 (1989).

6. Ostrom, J. H. The osteology of Compsognathus longpipes Wagner. Zitteliana 4, 73-118 (1978).

7. Chen, P.-j., Dong, Z.-m. \& Zhen, S.-n. An exceptionally well-preserved theropod dinosaur from the Yixian Formation of China. Nature 391, 147-152 (1998).

8. Wellnhofer, P. A new specimen of Archaeopteryx from the Solnhofen Limestone. Nat. Hist. Mus. Los Angeles County Sci. Ser. 36, 3-23 (1992).

9. Sereno, P. C. \& Rao, C. G. Early evolution of avian flight and perching: new evidence from the Lower Cretaceous of China. Science 255, 845-848 (1992).

10. Zhou, Z. H. in Sixth Symposium on Mesozoic Terrestrial Ecosystems and Biota, Short Papers (eds Sun, A. \& Wang, Y.) 209-214 (China Ocean, Beijing, 1995).

11. Ji, Q. \& Ji, S. A. Protarchaeopterygid bird (Protarchaeopteryx gen. nov.)—fossil remains of archaeopterygids from China. Chinese Geol. 238, 38-41 (1997).

12. Wellnhofer, P. Das fünfte skelettexemplar von Archaeopteryx. Palaeontogr. A 147, 169-216 (1974).

13. Wellnhofer, P. Das siebte Examplar von Archaeopteryx aus den Solnhofener Schichten. Archaeopteryx 11, 1-48 (1993).

14. Hou, L. H. A carinate bird from the Upper Jurassic of western Liaoning, China. Chinese Sci. Bull. 42, 413-416 (1997).

15. Dong, Z. M. A lower Cretaceous enantiornithine bird from the Ordos Basin of Inner Mongolia, People's Republic of China. Can. J. Earth Sci. 30, 2177-2179 (1993).

16. Forster, C. A., Sampson, S. D. Chiappe, L. M. \& Krause, D. W. The theropod ancestry of birds: new evidence from the Late Cretaceous of Madagascar. Science 279, 1915-1919 (1998).

17. Chiappe, L. M., Norell, M. A. \& Clark, J. M. The skull of a relative of the stem-group bird Mononykus. Nature 392, 275-278 (1998).

18. Norell, M. A. \& Makovicky, P. Important features of the dromaeosaur skeleton: information from a new specimen. Am. Mus. Novit. 3215, 1-28 (1997).

19. Perle, A., Chiappe, L. M., Barsbold, R., Clark, J. M. \& Norell, M. Skeletal morphology of Mononykus olecranus (Theropoda: Avialae) from the Late Cretaceous of Mongolia. Am. Mus. Novit. 3105, 1-29 (1994).

20. Zhou, Z. H. The discovery of Early Cretaceous birds in China. Courier Forschungsinstitut Senckenberg 181, 9-22 (1995)

21. Holtz, T. R. Jr The phylogenetic position of the Tyrannosauridae: implications for theropod systematics. J. Paleontol. 68, 1100-1117 (1994).

22. deBeer, G. Archaeopteryx lithographica. Br. Mus. Nat. Hist. 244, 1-68 (1954).

23. Feduccia, A. \& Tordoff, H. B. Feathers of Archaeopteryx: asymmetric vanes indicate aerodynamic function. Science 203, 1021-1022 (1979).

24. Chiappe, L. M. in The Encyclopedia of Dinosaurs (eds Currie, P. J. \& Padian, K.) 32-38 (Academic, San Diego, 1997).

25. Swofford, D. \& Begle, D. P. Phylogenetic Analysis Using Parsimony. Version 3.1.1. (Smithsonian Institution, Washington DC, 1993)

26. Gauthier, J. in The Origin of Birds and the Evolution of Flight (ed. Padian, K.) 1-55 (Calif. Acad. Sci., San Francisco, 1986).

27. Holtz, T. R. Jr Phylogenetic taxonomy of the Coelurosauria (Dinosauria: Theropoda). J. Paleontol. 70, 536-538 (1996).

28. Owen, R. On the Archaeopteryx of von Meyer, with a description of the fossil remains of a long-tailed species, from the Lithographic Stone of Solenhofen. Phil. Trans., Lond. 153, 33-47 (1863).

29. Hou, L. H. A late Mesozoic bird from Inner Mongolia. Vert. PalAsiatica 32, 258-266 (1994).

30. Kurochkin, E. N. A true carinate bird from Lower Cretaceous deposits in Mongolia and other evidence of Early Cretaceous birds in Asia. Cretaceous Res. 6, 271-278 (1985).

31. Sanz, J. L., Bonapart, J. F. \& Lacasa, A. Unusual Early Cretaceous birds from Spain. Nature 331, 433 435 (1988).

32. Kellner, A. W. A., Maisey, J. G. \& Campos, D. A. Fossil down feather from the Lower Cretaceous of Brazil. Palaeontol. 37, 489-492 (1994).

33. Grimaldi, D. \& Case, G. R. A feather in amber from the Upper Cretaceous of New Jersey. Am. Mus. Novit. 3126, 1-6 (1995).

Supplementary information is available on Nature's World-Wide Web site (http://www.nature.com) or as paper copy from the London editorial office of Nature.

Acknowledgements. We thank A. Brush, B. Creisler, M. Ellison, W.-D. Heinrich, N. Jacobsen, E. and R. Koppelhus, P. Makovicky, A. Milner, G. Olshevsky, J. Ostrom and H.-P. Schultze for advice, access to collections and logistic support; and the National Geographic Society, National Science Foundation (USA), the American Museum of Natural History, National Natural Science Foundation of China and the Ministry of Geology for support. Photographs were taken by O. L. Mazzatenta and K. Aulenback; the latter was also responsible for preliminary preparation of the Caudipteryx specimens. Line drawings are by P.J.C.

Correspondence and requests for materials should be addressed to P.J.C. (e-mail: pcurrie@mcd. gov.ab.ca). 